\title{
Normal FGF-21-Serum Levels in Patients with Carnitine Palmitoyltransferase II (CPT II) Deficiency
}

\author{
Leila Motlagh Scholle*, Diana Lehmann, Pushpa Raj Joshi and Stephan Zierz \\ Department of Neurology, Martin-Luther-University Halle-Wittenberg, Ernst-Grube-Str. 40, \\ 06120 Halle (Saale), Germany; diana.lehmann@rku.de (D.L.); pushpa.joshi@medizin.uni-halle.de (P.R.J.); \\ stephan.zierz@uk-halle.de (S.Z.) \\ * Correspondence: leila.scholle@medizin.uni-halle.de; Tel.: +49-345-557-3628; Fax: +49-345-557-3505
}

Received: 8 February 2019; Accepted: 18 March 2019; Published: 20 March 2019

\begin{abstract}
Fibroblast growth factor 21 (FGF-21) is known to be a biomarker for mitochondrial disorders. An upregulation of FGF-21 in serum and muscle of carnitine palmitoyltransferase I (CPT I) and carnitine palmitoyltransferase II (CPT II) knock-out mice has been reported. In human CPT II deficiency, enzyme activity and protein content are normal, but the enzyme is abnormally regulated by malonyl-CoA and is abnormally thermolabile. Citrate synthase (CS) activity is increased in patients with CPT II deficiency. This may indicate a compensatory response to an impaired function of CPT II. In this study, FGF-21 serum levels in patients with CPT II deficiency during attack free intervals and in healthy controls were measured by enzyme linked immunosorbent assay (ELISA). The data showed no significant difference between FGF-21 concentration in the serum of patients with CPT II deficiency and that in the healthy controls. The results of the present work support the hypothesis that in muscle CPT II deficiency, in contrast to the mouse knockout model, mitochondrial fatty acid utilization is not persistently reduced. Thus, FGF-21 does not seem to be a useful biomarker in the diagnosis of CPT II deficiency.
\end{abstract}

Keywords: FGF-21; mitochondrial diseases; carnitine palmitoyltransferase II deficiency; biomarker

\section{Introduction}

FGF-21 was first introduced in 2011 as a biomarker for the diagnosis of mitochondrial diseases [1]. This idea has subsequently been confirmed in various other studies [2-6]. The increased expression of FGF-21 in mitochondrial disorders is believed to be a compensatory response to respiratory chain deficiency [7]. In some metabolic diseases other than mitochondrial disorders, like in patients with obesity and type 2 diabetes, the serum or plasma levels of FGF-21 have been reported to be elevated [8].

The $\beta$-oxidation of activated fatty acids occurs in the mitochondrial matrix $[9,10]$. For transport of long chain fatty acids through the mitochondrial inner membrane, a special transport system is needed, including CPT I and CPT II. CPT II deficiency is regarded as the most common defect of lipid metabolism in skeletal muscle. CPT II is a ubiquitous protein without tissue specificity [10,11].

FGF-21 knockout mice (Fgf21 ${ }^{-/}$) have been shown to not be able to mobilize and utilize lipids out of a ketogenic diet [12]. The Fgf $21^{-/-}$mice showed significantly increased levels of FGF-21 in serum in both fed and fasted states. The mRNA expression of FGF-21 was upregulated in several muscles of these CPT I deficient mice [13].

Mice with liver-specific knockout of CPT II (Cpt $\left.2^{\mathrm{L}-/-}\right)$ have been shown to have elevated mRNA expressions of $g d f 15$ and $f g f 21$ genes and increased serum FGF-21 and Growth/Differentiation factor (GDF)-15 concentrations following high-fat-feeding $[14,15]$. Another group of mice with an adipose-specific knockout of CPT II (CPT2 ${ }^{\mathrm{A}-/-}$ ) [16] was shown to have an increased expression of mRNA of $f g f 21$ in brown adipose tissue (BAT) following cold exposure [17]. 
The human muscle form of CPT II-deficiency is characterized by attacks of myalgia and myoglobinura provoked by prolonged exercise, fasting, fever, or exposure to cold $[11,18]$. In about $90 \%$ of patients a p.S113L mutation can be found with an allele frequency of $60-70 \%$ [19]. More than 60 other mutations have been identified in patients with CPT II- deficiency [20].

Until now, there have been no studies performed on FGF-21 serum levels in CPT II deficient patients. Our data showed that in contrast to the knockout mouse model, FGF-21 serum levels in patients with CPT II deficiency were not different from those in healthy controls.

\section{Results}

The cut-off concentration of FGF-21 for normal controls was set at $190 \mathrm{pg} / \mathrm{mL}$ based on the results of the 95th percentile of controls. None of the 13 CPT II patients had elevated FGF-21 serum concentrations (Table 1). For the whole group of patients, FGF-21 serum concentrations were not significantly different from those of the controls. None of the patients showed an FGF-21 concentration above the cut-off value (Figure 1). Spearman rank correlation coefficient testing showed no significant correlation between FGF-21 concentration and body mass index (BMI) (Spearman correlation ( $r s=0.46$, $p=0.11$ ). There was also no significant correlation between the FGF-21 concentration and the frequency of attacks within one year ( $\mathrm{rs}=0.15, p=0.62)$.

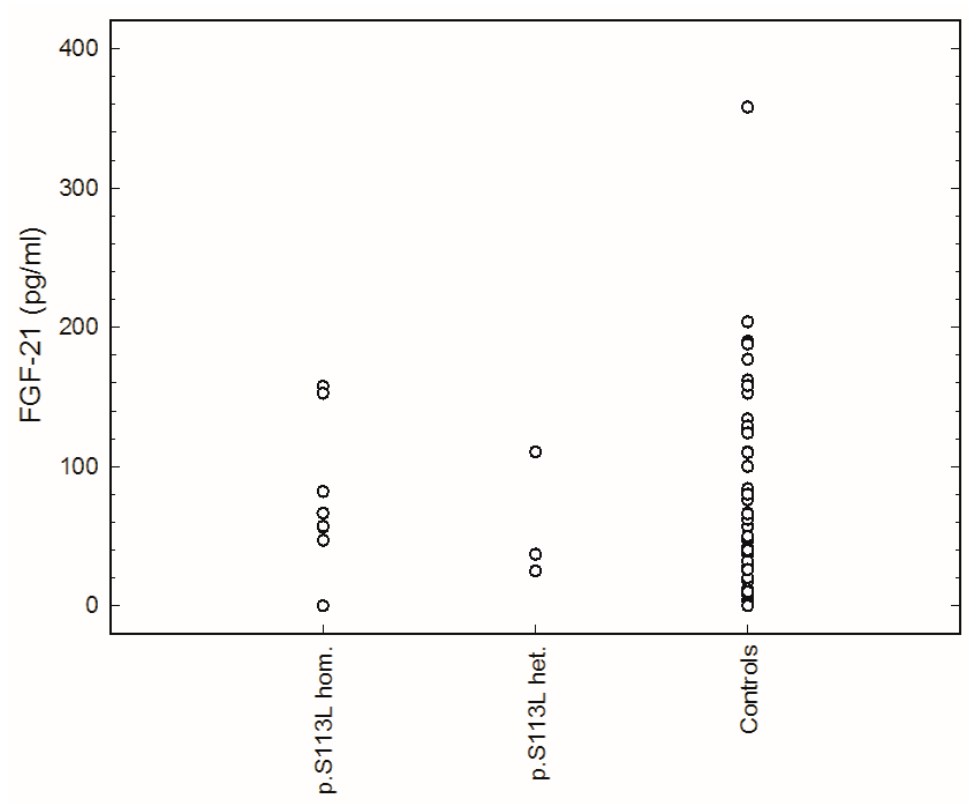

Figure 1. Fibroblast growth factor 21 (FGF-21) serum concentration in controls and patients with carnitine palmitoyltransferase II (CPT II) deficiency (p.S113L hom.: patients homozygous for the common p.S113L mutation; p.S113L het.: Patients with p.S113L on one allele and another mutation on other allele. The detailed genotype of all patients is illustrated in Table 1). 
Table 1. Epidemiological data of patients.

\begin{tabular}{|c|c|c|c|c|c|c|c|c|}
\hline Patients & Gender & $\begin{array}{c}\text { Age at } \\
\text { Diagnosis (yrs.) }\end{array}$ & $\begin{array}{l}\text { Age of First } \\
\text { Attack (yrs.) }\end{array}$ & $\begin{array}{l}\text { Attacks Per } \\
\text { Year }(n)\end{array}$ & $\begin{array}{c}\text { Intensity of } \\
\text { Pain* }\end{array}$ & BMI & Genotype & FGF-21 (pg/mL) \\
\hline 1 & $\mathrm{~F}$ & 19 & 6 & 5 & 3 & 23.9 & p.Ser113Leu/p.Ser113Leu & 47.0 \\
\hline 2 & $\mathrm{~F}$ & 34 & 6 & 1 & 4 & 25.9 & p.Ser113Leu/p.Ser113Leu & 66.5 \\
\hline 3 & M & 33 & 8 & 1 & 4 & 26.6 & p.Ser113Leu/p.Ser113Leu & 152.5 \\
\hline 4 & M & 53 & 8 & 7 & 7 & 27.1 & p.Ser113Leu/p.Ser113Leu & 82.0 \\
\hline 5 & M & 21 & 10 & 7 & 4 & 24.2 & p.Ser113Leu/p.Ser113Leu & 57.0 \\
\hline 6 & M & 54 & 5 & 1 & 7 & 24.2 & p.Ser113Leu/c.1238delAG & 37.0 \\
\hline 7 & M & 25 & 4 & 85 & 4 & 30.7 & p.Ser113Leu/c.340 + 1G > A & 110.5 \\
\hline 8 & M & 24 & 9 & 10 & 7 & 26.6 & p.Ser113Leu/c.340 + 5G > A & 25.5 \\
\hline 9 & M & 45 & 10 & 1 & 4 & 30.0 & p.Ser113Leu/c.182_203del22 & 56.5 \\
\hline 10 & M & 22 & 10 & 1 & 4 & 26.4 & p.Arg231Trp/p.Glu487Lys & 12.0 \\
\hline 11 & M & 57 & 17 & 11 & 5 & 24.9 & p.Ser113Leu/p.Ser113Leu & 0 \\
\hline 12 & $\mathrm{~F}$ & 53 & 18 & 50 & 4 & 27.9 & p.Ser113Leu/p.Arg151Gln & 57.5 \\
\hline 13 & $\mathrm{~F}$ & 39 & 15 & 6 & 5 & 20.4 & p.Ser113Leu/p.Pro50His & 57.0 \\
\hline Mean & & & & 8.8 & & 26.3 & & 66.2 \\
\hline Range (CI) & & & & $6.1-11.5$ & & $25.0-27.7$ & & $36.8-95.6$ \\
\hline \multicolumn{2}{|c|}{ Controls (FGF-21) } & & & & & & Range (CI) & Mean \\
\hline \multicolumn{2}{|c|}{ All $(n=50)$} & & & & & & $46.4-90.6$ & 68.5 \\
\hline \multicolumn{2}{|c|}{$M(n=23)$} & & & & & & $52.8-108.9$ & 80.9 \\
\hline \multicolumn{2}{|c|}{$\mathrm{F}(n=27)$} & & & & & & 23.4-92.4 & 57.9 \\
\hline
\end{tabular}

F: female, M: male; BMI: body mass index; *: intensity of pain on a visual analogue scale (VAS) (0: no pain at all, 10: unbearable severe pain) during an attack; CI: $95 \%$ confidence interval. 


\section{Discussion}

In mouse models with liver- and adipose-specific knockout of CPT II (Cpt2 $\left.{ }^{\mathrm{L}-/-}\right)\left(\mathrm{CPT} 2^{\mathrm{A}-/-}\right)$, an increase in mRNA expression of Fgf21 genes has been found following high-fat-feeding or exposure to cold [15-17]. A significant increase in mtDNA copy number after treatment of C2C12 myoblasts with FGF-21 has been reported. Additionally, the expression of CPT1A, CPT II genes, and citrate synthase activity also increased (1.5 times) [7]. These data suggest an adopting role of FGF-21 in response to a loss of mitochondrial fatty acid oxidation, which has been interpreted as a compensatory process in order to maintain the energy supply in affected tissues $[13,15]$.

Based on these findings, a higher FGF-21 serum level could also be expected in CPT II deficient patients. However, in the present study no significant difference was found in FGF-21 serum concentration between CPT II deficient patients and the controls. This outcome can be explained by the following differences between the knock out models and human muscle CPT II deficiency: (i) in contrast to knockout models, there is no loss of CPT II activity in patients $[19,21]$ and (ii) unlike in knockout models there is no reduction of protein concentrations of CPT I and CPT II in patients [22]. The genotypes of the patients are typical for human muscle deficiency. In the mouse model, however, the whole gene is knocked out. Thus, the genotypes are not comparable.

The increased citrate synthase activity in the muscles of patients might indicate the increased mitochondrial compartment compensating for the functional impairment in CPT II deficiency [22-24].

It has been suggested that the increase in FGF-21 concentrations in serum might occur with increasing clinical severity, progression of mitochondrial disease, and muscle pathology $[1,3,4]$.

The human muscle form of CPT II deficiency is characterized by attacks of myalgia and myoglobinura, provoked by prolonged exercise, fasting, fever, or exposure to cold [11,18].

One possible limitation of our study might be the small number of 13 patients. However, human muscle CPT II deficiency is a rare disease with very low prevalence. Thus the number of 13 patients included in our study is exceptionally high compared to other biochemical and molecular studies on CPT II deficiencies.

It should be noted that the serum samples from our patients were collected during attack-free intervals. Hence, the only attack-like impairment of fatty acid utilization in patients with the muscle form of CPT II deficiency might not have been sufficient to cause an increased FGF-21, at least during attack-free intervals. This is consistent with the notion that in human muscle CPT II deficiency there is no permanent lack of the enzymatic active enzyme but rather an abnormal regulation and thermoinstability of the mutant enzyme $[25,26]$.

\section{Materials and Methods}

\subsection{Patients and Controls}

Thirteen patients with a genetically confirmed diagnosis of CPT II deficiency (four females and nine males) were included in the study (Table 1), with their ages at the time of analysis ranging 28-80 years (mean: 46.9 years). The clinical and molecular data of all patients have previously been reported in detail [16].

Fifty healthy individuals ( 27 females and 23 males) with no clinical or molecular evidence of mitochondrial disorder served as controls. The ages of the controls ranged 21-73 years (mean: 41 years).

The study was performed in accordance with the Helsinki Declaration. The study was approved by the ethics committee of the Medical Faculty of the Martin-Luther-University Halle-Wittenberg on 8 September 2012. Written informed consent was received from all patients.

\subsection{Measurement of FGF-21 Serum Concentration}

FGF-21 serum concentration was measured in duplicate samples using ELISA (BioVendor, Brno, Czech Republic) according to the manufacturer's instructions. A standard curve was created as 
described in the manual of the company BioVendor. The absolute concentration of FGF-21 in all samples was determined according to a linear standard curve.

The samples from patients were obtained during asymptomatic intervals. All samples were stored at $-80{ }^{\circ} \mathrm{C}$ until analysis. The undetectable level was set as $0 \mathrm{pg} / \mathrm{mL}$.

Author Contributions: L.M.S. designed and performed the experiments and wrote the manuscript. P.R.J. and D.L. performed the experiments and wrote the manuscript. S.Z. designed the experiments and wrote the manuscript.

Funding: This work was funded by the Deutsche Gesellschaft für Muskelkranke (DGM) e.V. (www.dgm.org). The APC was also funded by the German Research Foundation (DFG) in the funding program Open Access Publishing.

Conflicts of Interest: The authors declare no conflict of interest.

\section{References}

1. Suomalainen, A. Biomarkers for mitochondrial respiratory chain disorders. J. Inherit. Metab. Dis. 2011, 34, 277-282. [CrossRef] [PubMed]

2. Scholle, L.M.; Lehmann, D.; Deschauer, M.; Kraya, T.; Zierz, S. FGF-21 as a Potential Biomarker for Mitochondrial Diseases. Curr. Med. Chem. 2018, 25, 2070-2081. [CrossRef] [PubMed]

3. Davis, R.L.; Liang, C.; Edema-Hildebrand, F.; Riley, C.; Needham, M.; Sue, C.M. Fibroblast growth factor 21 is a sensitive biomarker of mitochondrial disease. Neurology 2013, 81, 1819-1826. [CrossRef] [PubMed]

4. Koene, S.; de Laat, P.; van Tienoven, D.H.; Vriens, D.; Brandt, A.M.; Sweep, F.C.; Rodenburg, R.J.; Donders, A.R.; Janssen, M.C.; Smeitink, J.A. Serum FGF21 levels in adult m.3243A>G carriers: Clinical implications. Neurology 2014, 83, 125-133. [CrossRef] [PubMed]

5. Morovat, A.; Weerasinghe, G.; Nesbitt, V.; Hofer, M.; Agnew, T.; Quaghebeur, G.; Sergeant, K.; Fratter, C.; Guha, N.; Mirzazadeh, M. Use of FGF-21 as a Biomarker of Mitochondrial Disease in Clinical Practice. J. Clin. Med. 2017, 6, 80. [CrossRef]

6. Suomalainen, A.; Elo, J.M.; Pietilainen, K.H.; Hakonen, A.H.; Sevastianova, K.; Korpela, M.; Isohanni, P.; Marjavaara, S.K.; Tyni, T.; Kiuru-Enari, S.; et al. FGF-21 as a biomarker for muscle-manifesting mitochondrial respiratory chain deficiencies: A diagnostic study. Lancet Neurol. 2011, 10, 806-818. [CrossRef]

7. Ji, K.; Zheng, J.; Lv, J.; Xu, J.; Ji, X.; Luo, Y.B.; Li, W.; Zhao, Y.; Yan, C. Skeletal muscle increases FGF21 expression in mitochondrial disorders to compensate for energy metabolic insufficiency by activating the mTOR-YY1-PGC1alpha pathway. Free Radic. Biol. Med. 2015, 84, 161-170. [CrossRef] [PubMed]

8. Mraz, M.; Bartlova, M.; Lacinova, Z.; Michalsky, D.; Kasalicky, M.; Haluzikova, D.; Matoulek, M.; Dostalova, I.; Humenanska, V.; Haluzik, M. Serum concentrations and tissue expression of a novel endocrine regulator fibroblast growth factor-21 in patients with type 2 diabetes and obesity. Clin. Endocrinol. 2009, 71, 369-375. [CrossRef]

9. Eaton, S.; Bartlett, K.; Pourfarzam, M. Mammalian mitochondrial beta-oxidation. Biochem. J. 1996, 320 Pt 2, 345-357. [CrossRef]

10. Kerner, J.; Hoppel, C. Fatty acid import into mitochondria. Biochim. Biophys. Acta (BBA) Mol. Cell Biol. Lipids 2000, 1486, 1-17. [CrossRef]

11. McGarry, J.D.; Brown, N.F. The mitochondrial carnitine palmitoyltransferase system. From concept to molecular analysis. Eur. J. Biochem. 1997, 244, 1-14. [CrossRef]

12. Badman, M.K.; Koester, A.; Flier, J.S.; Kharitonenkov, A.; Maratos-Flier, E. Fibroblast growth factor 21-deficient mice demonstrate impaired adaptation to ketosis. Endocrinology 2009, 150, 4931-4940. [CrossRef]

13. Vandanmagsar, B.; Warfel, J.D.; Wicks, S.E.; Ghosh, S.; Salbaum, J.M.; Burk, D.; Dubuisson, O.S.; Mendoza, T.M.; Zhang, J.; Noland, R.C.; et al. Impaired Mitochondrial Fat Oxidation Induces FGF21 in Muscle. Cell Rep. 2016, 15, 1686-1699. [CrossRef]

14. Lee, J.; Choi, J.; Scafidi, S.; Wolfgang, M.J. Hepatic Fatty Acid Oxidation Restrains Systemic Catabolism during Starvation. Cell Rep. 2016, 16, 201-212. [CrossRef]

15. Lee, J.; Choi, J.; Selen Alpergin, E.S.; Zhao, L.; Hartung, T.; Scafidi, S.; Riddle, R.C.; Wolfgang, M.J. Loss of Hepatic Mitochondrial Long-Chain Fatty Acid Oxidation Confers Resistance to Diet-Induced Obesity and Glucose Intolerance. Cell Rep. 2017, 20, 655-667. [CrossRef] 
16. Lee, J.; Ellis, J.M.; Wolfgang, M.J. Adipose fatty acid oxidation is required for thermogenesis and potentiates oxidative stress-induced inflammation. Cell Rep. 2015, 10, 266-279. [CrossRef]

17. Gonzalez-Hurtado, E.; Lee, J.; Choi, J.; Wolfgang, M.J. Fatty acid oxidation is required for active and quiescent brown adipose tissue maintenance and thermogenic programing. Mol. Metab. 2018, 7, 45-56. [CrossRef]

18. Joshi, P.R.; Deschauer, M.; Zierz, S. Phenotype of carnitine palmitoyltransferase II (CPT II) deficiency: A questionnaire-based survey. J. Clin. Neurosci. 2019, 59, 32-36. [CrossRef]

19. Deschauer, M.; Wieser, T.; Zierz, S. Muscle carnitine palmitoyltransferase II deficiency: Clinical and molecular genetic features and diagnostic aspects. Arch. Neurol. 2005, 62, 37-41. [CrossRef]

20. Isackson, P.J.; Bennett, M.J.; Vladutiu, G.D. Identification of 16 new disease-causing mutations in the CPT2 gene resulting in carnitine palmitoyltransferase II deficiency. Mol. Genet. Metab. 2006, 89, 323-331. [CrossRef]

21. Zierz, S.; Engel, A.G. Regulatory properties of a mutant carnitine palmitoyltransferase in human skeletal muscle. Eur. J. Biochem. 1985, 149, 207-214. [CrossRef]

22. Lehmann, D.; Zierz, S. Normal protein content but abnormally inhibited enzyme activity in muscle carnitine palmitoyltransferase II deficiency. J. Neurol. Sci. 2014, 339, 183-188. [CrossRef]

23. Larsen, S.; Nielsen, J.; Hansen, C.N.; Nielsen, L.B.; Wibrand, F.; Stride, N.; Schroder, H.D.; Boushel, R.; Helge, J.W.; Dela, F.; et al. Biomarkers of mitochondrial content in skeletal muscle of healthy young human subjects. J. Physiol. 2012, 590, 3349-3360. [CrossRef]

24. Molina, A.J.; Bharadwaj, M.S.; Van Horn, C.; Nicklas, B.J.; Lyles, M.F.; Eggebeen, J.; Haykowsky, M.J.; Brubaker, P.H.; Kitzman, D.W. Skeletal Muscle Mitochondrial Content, Oxidative Capacity, and Mfn2 Expression Are Reduced in Older Patients with Heart Failure and Preserved Ejection Fraction and Are Related to Exercise Intolerance. JACC Heart Fail. 2016, 4, 636-645. [CrossRef]

25. Motlagh, L.; Golbik, R.; Sippl, W.; Zierz, S. Malony-CoA inhibits the S113L variant of carnitine-palmitoyltransferase II. Biochim. Biophys. Acta 2016, 1861, 34-40. [CrossRef]

26. Motlagh, L.; Golbik, R.; Sippl, W.; Zierz, S. Stabilization of the thermolabile variant S113L of carnitine palmitoyltransferase II. Neurol. Genet. 2016, 2, e53. [CrossRef]

(C) 2019 by the authors. Licensee MDPI, Basel, Switzerland. This article is an open access article distributed under the terms and conditions of the Creative Commons Attribution (CC BY) license (http:/ / creativecommons.org/licenses/by/4.0/). 